\title{
High Resolution Mapping of a Novel Late Blight Resistance Gene Rpi-avl1, from the Wild Bolivian Species Solanum avilesii
}

\author{
Estelle Verzaux • Dirk Budding • Nick de Vetten • \\ Rients E. Niks • Vivianne G. A. A. Vleeshouwers • \\ Edwin A. G. van der Vossen - Evert Jacobsen • \\ Richard G. F. Visser
}

Published online: 1 November 2011

(C) The Author(s) 2011. This article is published with open access at Springerlink.com

\begin{abstract}
Both Mexico and South America are rich in Solanum species that might be valuable sources of resistance $(R)$ genes to late blight (Phytophthora infestans). Here, we focus on an $R$ gene present in the diploid Bolivian species $S$. avilesii. The genotype carrying the $R$ gene was resistant to eight out of 10 Phytophthora isolates of various provenances. The identification of a resistant phenotype and the generation of a segregating population allowed the mapping of a single dominant $R$ gene, Rpi-avll, which is located in an $R$ gene cluster on chromosome 11 . This $R$ gene cluster is considered as an $R$ gene "hot spot", containing $R$ genes to at least five different pathogens. High resolution mapping of the Rpi-avl1 gene revealed a marker co-segregating in $3890 \mathrm{~F}_{1}$ individuals, which may be used for marker assisted selection in breeding programs and for further cloning of Rpi-avll.
\end{abstract}

Resumen Tanto México como Sudamérica son ricos en especies de Solanum que pudieran ser valiosas fuentes de

E. Verzaux $\cdot$ D. Budding $\cdot$ R. E. Niks $\cdot$

V. G. A. A. Vleeshouwers • E. A. G. van der Vossen •

E. Jacobsen $\cdot$ R. G. F. Visser $(\varangle)$

Wageningen UR Plant Breeding,

Wageningen University \& Research Center,

Wageningen, The Netherlands

e-mail: Richard.Visser@wur.nl

N. de Vetten

Averis Seeds B.V.,

Valthermond, The Netherlands

Present Address:

E. A. G. van der Vossen

Keygene N.V.,

Agrobusiness Park 90,

6708 PW Wageningen, The Netherlands genes de resistencia (R) al tizón tardío (Phytophthora infestans). Aquí nos enfocamos en un gene $\mathrm{R}$ presente en la especie diploide Boliviana $S$. avilesii. El genotipo que contiene el gene $\mathrm{R}$ fue resistente a ocho de 10 aislamientos de Phytophthora de varias localidades. La identificación de un fenotipo resistente y la generación de una población segregante permitieron el mapeo de un gene $\mathrm{R}$ simple dominante, Rpi-av11, que se localiza en un agrupamiento de genes del cromosoma 11. Este grupo de gene $\mathrm{R}$ se considera como un punto clave de este gene, con un contenido de genes $\mathrm{R}$ para por lo menos cinco diferentes patógenos. El mapeo de alta resolución del gene Rpi-av11 reveló a un marcador co-segregando en 3890 individuos de F1, que podría usarse para selección asistida de marcadores en programas de mejoramiento y para clonaciones posteriores de Rpi-av11.

Keywords Phytophthora infestans $\cdot$ Wild Solanum species $\cdot N$ cluster $\cdot$ Chromosome 11

\section{Introduction}

Late blight, caused by the oomycete pathogen Phytophthora infestans, is the most devastating disease for potato and tomato cultivation. Chemical control is currently the most reliable protection method, although this drastically increases the production costs and is not promoting sustainability. $P$. infestans is becoming increasingly aggressive (Haverkort et al. 2008). Since the Irish potato famine in the mid 19th century breeders have included late blight resistance in their potato breeding programs, first focusing on the introgression of dominant resistance $(R)$ genes from Solanum demissum, a hexaploid wild species originating from Mexico (Malcolmson 
and Black 1966; Wastie 1991). Following the breaking of resistance by fast changing strains of the pathogen, the focus moved to quantitative resistance, which by virtue of its polygenic character is expected to be more durable. However, phenotypic effects of the genes for quantitative resistance are small and much affected by environmental conditions. Hence, selection for increased levels of quantitative resistance is difficult (Leonards-Schippers et al. 1994). Breeders' interests moved back to the application of major $R$ genes, especially since the cloning and characterization of Rpi-blb1 or RB (van der Vossen et al. 2003; Song et al. 2003). That gene confers resistance to a very broad spectrum of $P$. infestans strains. The large number of Solanum species with high levels of resistance to late blight, offers good opportunities for resistance breeding. Stacking of complementary broad spectrum $\mathrm{R}$ genes may result in resistance that remains durably effective. The identification, characterization and isolation of such major $R$ genes and the judicious stacking into potato varieties appears today to be the main objective for late blight resistance breeding. For such stacking, breeders have two alternative approaches. Firstly, $R$ genes can be transferred to existing potato varieties by genetic transformation, but application of GM directive 2001/18/ EC in Europe hampers release of transgenic GM organisms. Secondly, breeders can also follow classical introgression breeding, combined with marker assisted selection in order to stack broad spectrum R-genes (Barone 2004; Collard et al. 2005). However, this stacking approach is still hampered by the problem of linkage drag (Jacobsen and Schouten 2007). Irrespective of what use one prefers mapping of $\mathrm{R}$ genes is a first step. So far many positions for R genes (especially those derived from $S$. demissum) (Gebhardt and Valkonen 2001) or $\mathrm{R}$ gene homologues (Bakker et al. 2011) have been published and they form a good starting point for determining the genomic location of $\mathrm{R}$ genes from wild species as well.

A good place to search for resistance is the center of origin of late blight where plant hosts co-evolved with the pathogen. Many wild Solanum species that evolved in Mexico or South America have been suggested as source of resistance to late blight (Hawkes 1990). Solanum species from both origins are expected to carry a diversity of $R$ genes that may be valuable for resistance breeding. In practice, the Mexican $S$. demissum and $S$. bulbocastanum are the best known examples of sources of late blight resistance, and thus far, mainly $R$ genes originating from Mexico have been used. Perhaps South American species evolved other $R$ genes with distinct recognition specificities, either in a known $R$ gene cluster with novel specificities or in novel $R$ gene clusters. $R$ genes with novel specificity to $P$. infestans would be very valuable to be introduced by transformation or marker assisted resistance breeding.
In this study we focused on the diploid species $S$. avilesii (avl) Hawkes \& Hjerting, which originates from Bolivia (Gabriel et al. 2001; Ruiz de Galarreta et al. 1998), and we mapped the first late blight $R$ gene from this species, called Rpi-avll, on the short arm of chromosome 11.

\section{Materials and Methods}

\section{Plant Material and Mapping Population}

Accessions of $S$. avilesii were provided by the Centre of Genetic Resources (CGN) in Wageningen, The Netherlands. A screen for resistance to $P$. infestans was performed on three $S$. avilesii accessions (477, 478 and 479, representing CGN 18255, CGN 18256 and CGN 18257, respectively), with five genotypes per accession. $\mathrm{Cv}$ Bintje and $S$. demissum clone dms 344-18 were used as susceptible and resistant control plants respectively. The genotype avl 478-2 was crossed with the susceptible genotype avl477-1 to generate an intraspecific F1 mapping population. A small population of 50 individuals was used to obtain a crude map position of the resistance gene (most importantly the chromosomal position) and later a large population of 3840 individuals of this same cross was used for fine mapping and development of a co-segregating marker.

\section{Phytophthora Isolates and Disease Test}

The P. infestans isolates 90128, IPO-C, H30P04, EC1, USA618, VK98014, IPO428-2, NL01096, F95573, and 89148-09 were kindly provided by Dr. Geert Kessel (PRI, Wageningen UR), Prof. Francine Govers (Laboratory of Phathology, Wageningen University) and Prof. Paul Birch (James Hutton Institute, Schotland). Resistance levels were assessed by three different assays, i.e. the in vitro assay, detached leaf assay (DLA), and field experiment. The in vitro assay was performed using $P$. infestans isolate 90128 (Huang 2005). Plantlets were visually scored after 1 and 2 weeks, and a score ranging from 9 (fully resistant) to 1 (susceptible) was applied.

The detached leaf assay was performed as described by Vleeshouwers et al. (1999). One leaf was harvested between the third and the fifth fully developed leaves, from 5 weeks old plants grown in the greenhouse, and inoculated with a zoospore suspension of the isolate of interest. The detached leaves were scored six days after inoculation. For initial germplasm screenings (Table 1), lesion sizes were measured. Lesion size (LS) was converted to a scale from 9 (resistant) to 1 (susceptible), with the resistance level of the susceptible control cultivar Bintje set at 2 (Table 1). For phenotyping of the parental genotypes with multiple 
Table 1 Resistance of $15 \mathrm{~S}$. avilesii genotypes from three different accessions to two Phytophthora infestans isolates 90128 and IPO-C, using three different assays: in vitro assay, detached leaf assay (DLA) and field experiments in 2 years. Resistance phenotypes were rated on the scale from 1 (highly susceptible) to 9 (highly resistant). avl for $S$. avilesii and $\mathrm{dms}$ for $S$. demissum. In grey, the genotypes used in DLA and field experiments, in bold the genotypes used in this study

\begin{tabular}{|c|c|c|c|c|c|c|}
\hline \multirow[t]{2}{*}{ Genotypes } & & \multirow{2}{*}{$\begin{array}{l}\text { In vitro } \\
90128\end{array}$} & \multicolumn{2}{|l|}{ DLA } & \multirow{2}{*}{$\begin{array}{l}\text { Field } 2005 \\
\text { IPO-C }\end{array}$} & \multirow{2}{*}{$\begin{array}{l}\text { Field } 2007 \\
\text { IPO-C }\end{array}$} \\
\hline & & & 90128 & IPO-C & & \\
\hline avl & $477-1$ & 1 & 3 & 3 & 6 & 6 \\
\hline avl & $477-2$ & 9 & nd & nd & nd & nd \\
\hline avl & $477-3$ & 1 & nd & nd & nd & nd \\
\hline avl & $477-4$ & 9 & 4 & 4 & 9 & nd \\
\hline avl & $477-5$ & 9 & nd & nd & nd & nd \\
\hline avl & $478-1$ & 1 & nd & nd & nd & nd \\
\hline avl & $478-2$ & 9 & 6 & 6 & 9 & 8 \\
\hline avl & $478-3$ & 3 & nd & nd & nd & nd \\
\hline avl & $478-4$ & 3 & nd & nd & nd & nd \\
\hline avl & $478-5$ & 1 & nd & nd & nd & nd \\
\hline avl & $479-1$ & 1 & nd & nd & nd & nd \\
\hline avl & $479-2$ & 1 & nd & nd & nd & nd \\
\hline avl & $479-3$ & 3 & nd & nd & nd & nd \\
\hline avl & $479-4$ & 1 & nd & nd & nd & nd \\
\hline avl & $479-5$ & 1 & nd & nd & nd & nd \\
\hline cv. Bintje & & 2 & 2 & 2 & 2 & 2 \\
\hline $\mathrm{dms}$ & $344-14$ & 9 & 9 & 9 & nd & nd \\
\hline $\mathrm{dms}$ & $344-18$ & nd & 9 & 9 & 9 & 9 \\
\hline
\end{tabular}

isolates and the F1 progeny with 90128 and USA618 (Table 2), macroscopic scoring was applied and leaves were scored as resistant $(\mathrm{R})$ when hypersensitive responses or no disease symptoms were observed, susceptible (S) when expanding lesions with sporulation were observed, or quantitative (Q) for a not clearly resistant nor susceptible response.

Two field trials were performed in the summers of 2005 and 2007, in Wageningen, the Netherlands, as described by Colon and Budding (1988). For comparisons between years, standard cultivars Ostara, Bildtstar, Eersteling, Pimpernel, Robijn and Biogold were included. Spreader rows consisted of potato cultivar Bintje, the border rows of cultivar Nicola. Disease assessments were made at weekly intervals. The percentage of leaf area covered with late blight lesions was estimated for each plot (Colon and Budding 1988). From these readings the area under the disease progress curve (AUDPC) was calculated (Fry 1978). The AUDPC values were transformed to a 9 (resistant) to 1 (susceptible) scale, relative to the largest AUDPC value.

\section{DNA Isolation}

Genomic DNA was isolated following two different protocols: $\mathrm{CTAB}$ and $\mathrm{NaOH}$. The CTAB protocol was performed on material that needed long storage like the mapping population and the interesting recombinants.
Table 2 List of Phytophthora infestans isolates used in the detached leaf assays with information on their origin and virulence spectrum. The phenotypes on the parental genotypes av1478-2 and 477-1 are characterized as resistant (R), susceptible (S) or unclear (Q). *(Champouret et al. 2009)

\begin{tabular}{lllll}
\hline P.i. isolate & Country of origin & Race* & avl478-2 & avl477-1 \\
\hline 90128 & The Netherlands & $1,3,4,7,8,10,11$ & $\mathrm{R}$ & $\mathrm{S}$ \\
H30P04 & The Netherlands & $3^{\mathrm{a}}, 7,10,11$ & $\mathrm{R}$ & $\mathrm{Q}$ \\
EC1 & Ecuador & $1,3,4,7,10,11$ & $\mathrm{R}$ & $\mathrm{S}$ \\
IPO-C & Belgium & $1,2,3,4,5,6,7,10,11$ & $\mathrm{R}$ & $\mathrm{S}$ \\
USA618 & Mexico & $1,2,3,6,7,10,11$ & $\mathrm{R}$ & $\mathrm{S}$ \\
VK98014 & The Netherlands & $1,2,4,11$ & $\mathrm{R}$ & $\mathrm{S}$ \\
IPO428-2 & The Netherlands & $1,3,4,7,8,10,11$ & $\mathrm{R}$ & $\mathrm{S}$ \\
NL01096 & The Netherlands & $1,3,4,7,8,10,11$ & $\mathrm{~S}$ & $\mathrm{~S}$ \\
F95573 & The Netherlands & $1,3,4,7,10,11$ & $\mathrm{~S}$ & $\mathrm{~S}$ \\
$89148-09$ & The Netherlands & 0 & $\mathrm{R}$ & $\mathrm{Q}$ \\
\hline
\end{tabular}


Young leaf tissue was collected for DNA isolation according to the CTAB protocol with the Retsch machine (RETSCH INC., Hannover, Germany). The $\mathrm{NaOH}$ protocol was used for screening for recombination events in the population. Leaf samples were collected on 3 weeks old seedlings and DNA was isolated by following the $\mathrm{NaOH}$ protocol (Wang et al. 1993). The PCR amplifications were directly performed on these samples.

\section{SSR Markers}

A set of 80 SSR markers covering all chromosomes of the potato genome (Collins et al. 1999; Feingold et al. 2005; Bakker et al. 2011; Ghislain et al. 2004) was applied. PCR reactions for the SSR markers were performed using a single PCR profile: an initial cycle at $95^{\circ} \mathrm{C}$ for $2 \mathrm{~min}$; then 30 cycles of $95^{\circ} \mathrm{C}$ for $30 \mathrm{~s}, 56^{\circ} \mathrm{C}$ for $30 \mathrm{~s}$, using a ramp of $1{ }^{\circ} \mathrm{C} / \mathrm{min}$, and $72^{\circ} \mathrm{C}$ for $45 \mathrm{~s}$, using a ramp of $1{ }^{\circ} \mathrm{C} / \mathrm{min}$; and a final step at $72^{\circ} \mathrm{C}$ for $3 \mathrm{~min}$. Subsequently the PCR products were visualized by electrophoresis on polyacrylamide gels on the LI-COR DNA sequencer (Lincoln, Nebraska, USA). Significantly linked markers based on $20 \mathrm{~F} 1$ individuals were subsequently tested on the complete population of 40 individuals with clear resistance or susceptibility for confirmation of the linkage.

\section{PCR Markers}

The primer pairs were first tested for amplification on the parents and screened with a selection of enzymes as described in Bai et al. (2004) for the identification of polymorphism between the resistant parent and the susceptible parent. The marker was later tested on the F1 individuals to determine the segregation pattern of the fragment and its association with the resistance phenotype. Genetic maps were drawn by using the number of recombination events between markers and between the markers and the resistant/susceptible phenotypes, knowing that one recombinant in 100 individuals corresponds to $1 \mathrm{cM}$.

\section{Development of Co-segregating Marker}

N-profiling markers were developed by following the NBS profiling protocol (a conserved domain in many $R$-genes cloned to date; van der Linden et al. 2004) and using tobacco mosaic virus resistance gene $N$-like specific primers (Dinesh-Kumar et al. 2000). First, a restriction ligation is performed on genomic DNA with a blunt enzyme and an adapter as described in van der Linden et al. (2004), which is subsequently amplified with the primers targeting the conserved sequence of interest and a primers annealing to the adapter. We designed a total of 15 primers (Table 4) based on $N$-like sequences. Eight degenerated primers were designed based on conserved regions from the different domains like TIR (Toll/Interleukin-1 Receptor), NBS (Nuclear Binding Site) and LRR (Leucine Rich Repeat) present in almost all cloned major R-genes to date, and seven non degenerated primers were designed based on the start codon region of several $N$-like sequences from the RH89-039-16 (RH) physical map (Borm 2008). These primers were used in combination with five enzymes generating blunt ends: AluI, HaeIII, RsaI, BspLI and HincII. The analysis was performed on the LI-COR DNA sequencer using fluorescent-labeled primers.

\section{Bulk Segregant Analysis}

An adapted bulk segregant analysis (BSA, Michelmore et al. 1991) was carried out. First, two bulks of 10 individuals without recombination between the closest markers (10 R and $10 \mathrm{~S}$ ) were selected to identify markers linked to the gene of interest. Second, two bulks of 10 individuals (10 R and $10 \mathrm{~S}$ ) with a recombination event between the two closest flanking markers on either side of the $R$ gene of interest were selected to identify closely linked or co-segregating markers. The identified linked markers were first tested on the F1 individuals of the bulks to confirm the linkage and then applied on the complete population for final validation.

\section{Recombinant Screening for Fine Mapping}

The F1 seeds were placed on 96 well format trays for germination in order to facilitate leave sampling and subsequent marker analysis. Two weeks after germination, the second true leaf was harvested and DNA isolated by following the $\mathrm{NaOH}$ protocol. The markers Ct182 and M33 and Gp163, flanking Rpi-avll, were applied on the freshly isolated DNA. In total 3840 individuals were screened for recombination events with these markers. Plants with a recombination between the flanking markers were transplanted to pots. CTAB DNA was isolated to confirm the recombination and test the markers co-segregating in the original population of 40 individuals showing clear resistance or susceptibility. Recombinant plants were tested for resistance, using late blight isolate 90128 in a detached leaf assay.

\section{Results}

Resistance in S. avilesii Accessions

To identify a resistant genotype for $R$ gene mapping and cloning, 5 genotypes from each of three $S$. avilesii accessions were tested for their resistance to $P$. infestans. The 15 individuals were first tested by an in vitro assay with isolate 90128. Four genotypes from two accessions (avl477-2; 
avl477-4; avl477-5 and avl478-2) gave a high level of resistance and all the other 11 genotypes showed clear susceptibility (Table 1). Among the five plants of accession 479 no resistance was observed. Two resistant genotypes, plant 4 from accession 477, and plant 2 from accession 478, and one susceptible genotype, plant 1 from accession 477 , were arbitrarily chosen to subsequently be tested in a detached leaf assay again with isolate 90128 , and with the additional isolate IPO-C. In this particular experiment, the plants were relatively old and almost flowering. The two resistant genotypes showed a medium level of resistance to both isolates (Table 1). However, in various subsequent Detached Leaf Assays (DLA) with younger plants, the genotype avl478-2 showed higher levels of resistance than avl477-4. The field experiments with the same genotypes revealed much higher levels of resistance to IPO-C than the DLA (Table 1). Avl478-2 (resistant) and avl477-1 (susceptible) were therefore selected for further investigation. The controls cv Bintje and genotype 18 from accession 344 of S. demissum showed in all 3 resistance assays the expected high level of susceptibility and resistance, respectively.

\section{P. infestans Resistance Spectrum in av1478-2 and avl477-1}

The spectrum of resistance of av1478-2 and av1477-1 was investigated in DLA with 11 P. infestans isolates from different origin and with varying virulence spectra. Macroscopically, avl478-2 showed resistance to nine of the 11 isolates tested, and susceptibility to the remaining two isolates (Table 2). The susceptible parent av1477-1 showed susceptibility to all the isolates tested, except to two isolates to which it showed intermediate phenotypes. Considering the genetically diverse set of isolates used in this experiment (Champouret et al. 2009), we conclude that $S$. avilesii plant av1478-2 is resistant to several isolates of diverse origins.

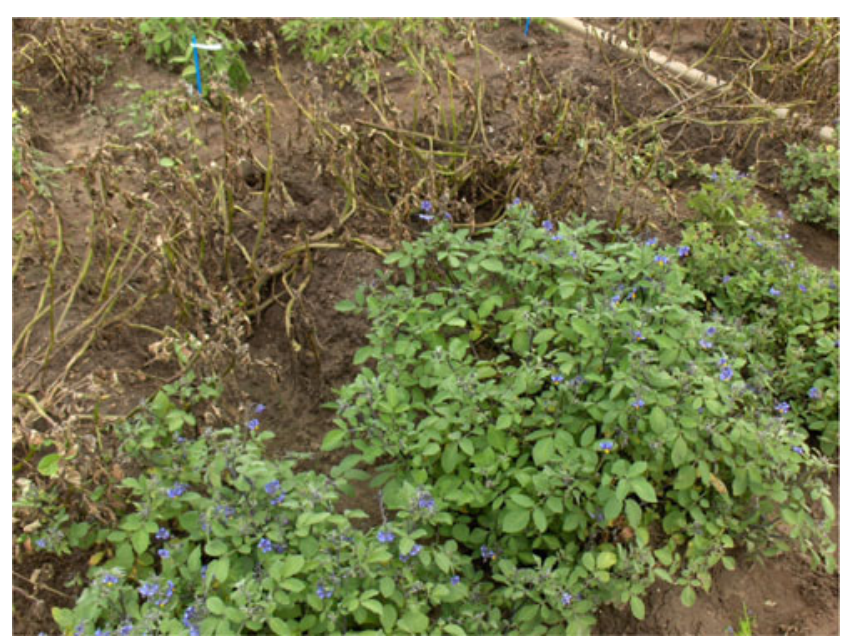

Fig. 1 Field experiment in 2007 with the resistant genotype av1478-2 next to the susceptible potato cultivar Bintje
Population Development

Resistant plant av1478-2 and susceptible plant avl477-1 were crossed to generate a mapping population. Fifty F1 individuals were tested for their resistance to P. infestans

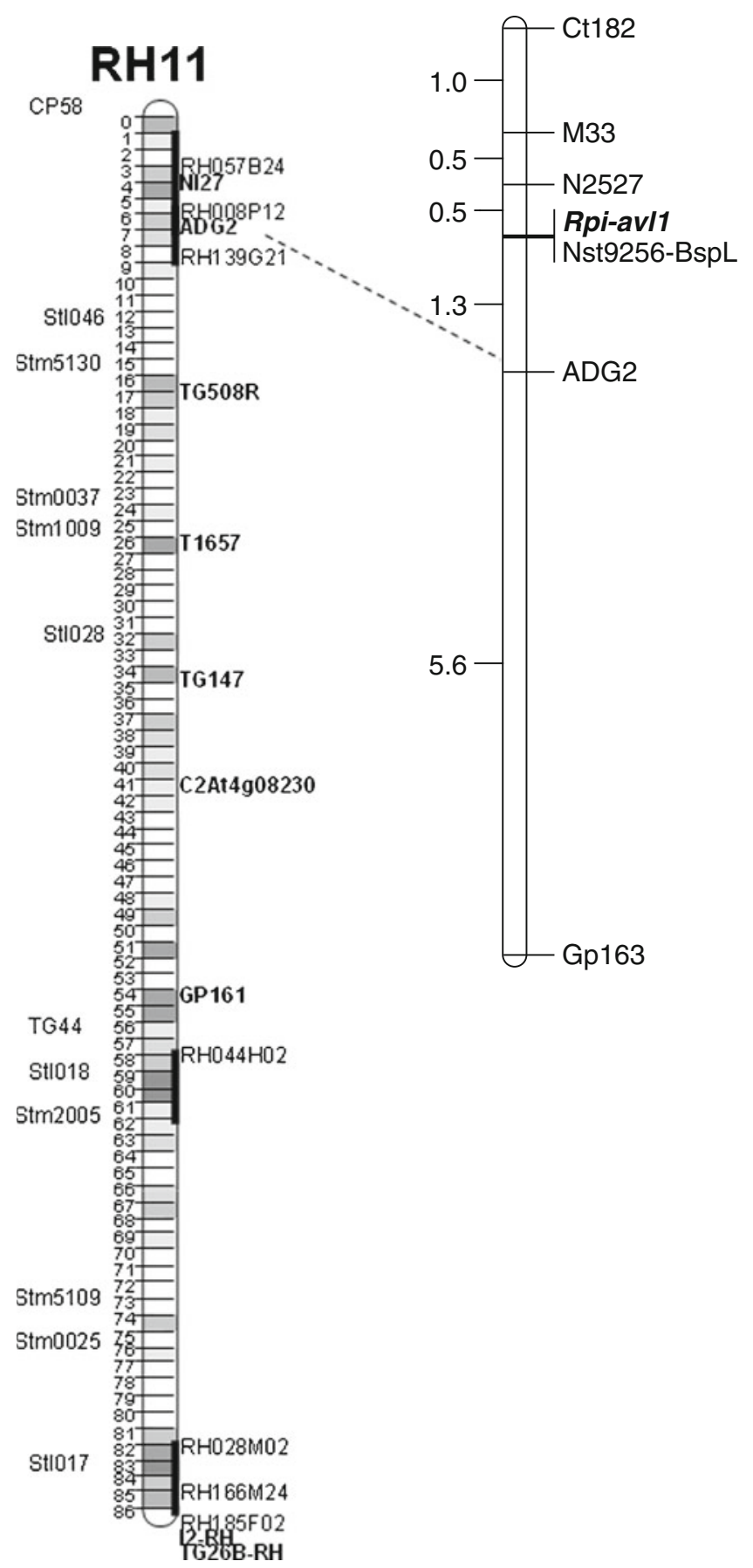

Fig. 2 Genetic map of the Rpi-avl1 locus (right) on chromosome 11 compared to the genetic map of RH on chromosome 11 (left). On the $\mathrm{RH}$ map, the numbers on the left indicate the bin numbers and available markers are located. The vertical black bars indicate $R$ gene clusters. On the Rpi-avll map, the numbers on the left indicate the distance in $\mathrm{cM}(n=3890)$ 
in a detached leaf assay with the isolates 90128 and USA618. Out of the 50 individuals, 17 were scored as resistant, 23 as susceptible and 10 individuals could not be characterized unambiguously. It appeared that the age of the plants might influence the resistance phenotype, resulting in this indiscrete segregation. It seemed that the plants have to be tested when young, i.e., before flowering, to give a reliable resistant or susceptible phenotype. The segregation of the resistance in the population suggested a $1: 1$ ratio $(p<0.05)$ which is consistent with the presence of a single dominant $R$ gene in the resistant parental plant avl478-2. We designate this gene Rpi-avll. This intraspecific F1 population of 40 genotypes was suitable and used to map the $R$ gene found in the resistant genotype avl478-2 (Fig. 1).

\section{Mapping of Rpi-avl1}

The screening of 22 independent samples, the two parents and $20 \mathrm{~F} 1$ individuals (10 resistant and 10 susceptible), with a set of approximately 80 SSRs spread over the 12 chromosomes resulted in one marker that was associated with the resistance. The other markers were either not polymorphic between the two parents, or not segregating in the population or not showing association with the resistance phenotype. The marker associated with the resistance phenotype, RH008P12 (Bakker et al. 2011), is located on the short arm of chromosome 11 (Fig. 2). Linkage with resistance was confirmed by genotyping the other 20 individuals with clear phenotype with the marker. The marker showed linkage with the resistance with 5 recombinants out of 40 individuals $(12 \mathrm{cM})$. This indicated that Rpi-avll is located on the short arm of chromosome 11. In that region a cluster of $R$ genes, conferring resistance to several pathogens, has been reported (Gebhardt and Valkonen 2001). Sequences with homology to the $N$ gene (Whitham et al. 1994) were earlier identified and considered as potential candidates for the $\mathrm{R}$ genes mapped in the cluster (Hehl et al. 1999; Vidal et al. 2002). To determine more precisely the position of Rpi-avll, more markers were developed from known CAPS markers previously described to be located on the short arm of chromosome 11. This lead to the development of the four markers Ct182, M33, ADG2 and Gp163 (Table 3). In parallel, the cDNA clones NL-25 and NL-27, which have homology to the tobacco mosaic virus resistance $N$ gene (Hehl et al. 1999) were used to design primers that specifically amplify only these sequences. This resulted in the development of the SCAR marker N2527 (Table 3). The N2527 primers amplified many homologous sequences of the same size (around $2 \mathrm{~kb}$ ) with an extra smaller fragment of around $1 \mathrm{~kb}$ on the resistant parent, linked in repulsion phase to the resistant phenotype. The three markers M33, ADG2 and N2527 cosegregated with the resistance in the population of 40 individuals. Ct182 was proximal and Gp163 was distal to Rpi-avl1 (Fig. 2).

\section{Fine Mapping of Rpi-avl1}

To map Rpi-avll at higher resolution, a larger population was required in order to obtain more recombination events. A recombinant screen was therefore performed on 3840 individuals with the flanking markers Ct182 and Gp163. 70 recombinant individuals were identified from the screening of the first seven 96 well plates (672 F1 individuals) and were characterized for their resistance phenotype. This allowed the separation between the previously co-segregating marker M33 and Rpi-avl1. M33 was proximal to the gene and therefore was used instead of $\mathrm{Ct} 182$ for the rest of the recombinant screen. In total 66 recombinant individuals were found between the markers M33 and Gp163 from the total screen of $3840 \mathrm{~F} 1$ individuals $(40 \times 96$ well plates). The resistance phenotype of these recombinants was determined, and the genetic map was constructed (Fig. 2). The closest flanking markers to Rpi-avll were the marker N2527 located 17 recombinants proximal to Rpi-avll $(0.5 \mathrm{cM})$, and ADG2 with 49 recombinants distal to the gene $(1.3 \mathrm{cM})$. The screen for recombinant F1 individuals resulted in a good set of recombinants for further marker development and potential map based cloning of Rpi-avll.
Table 3 PCR markers used in the Rpi-avll population, with primer sequences based on BAC sequences located on the short arm of chromosome 11 from the reference genotype $\mathrm{RH}$ or references for primers already published, annealing temperature (TM), and restriction enzyme to identify a polymorphism

${ }^{1}$ a.s., allele specific

\begin{tabular}{llll}
\hline Marker & Sequence or reference & Annealing temperature $\left({ }^{\circ} \mathrm{C}\right)$ & Enzyme $^{1}$ \\
\hline RH008P12 & $\begin{array}{l}\text { F gggtcgatgatccatttattg } \\
\text { R cccttttgttccatatcagttg }\end{array}$ & 56 & a.s. \\
N2527 & F gaaacacaggggaatattcacc & 60 & a.s. \\
& R ccatrtcttgwattaagtcatgc & & \\
Ct182 & (Brigneti et al. 1997) & 50 & HpyCH4IV \\
M33 & (Brigneti et al. 1997) & 55 & AluI \\
ADG2 & (Hämäläinen et al. 1998) & 55 & Cfr13I \\
Gp163 & (Brigneti et al. 1997) & 55 & Cfr13I \\
Nst9256-BspL & Nst9256-F: atggcatcttcttcttcttctttgcg & 55 & BspLI \\
\hline
\end{tabular}


Table 4 List of primers used for N-profiling

\begin{tabular}{lll}
\hline Primer name & Position on the gene & Sequence \\
\hline Nbs13-R & NBS & AAGAARCATGCDATATCTARAAATAT \\
Nbs12-R & NBS & YTTSARSGCTAAAGGRAGRCC \\
Nbs-12-F & NBS & CTTTAGCBYTSAARKTGTKKGG \\
Nbs15-F & NBS & ATGCATGAYTTRATWVAAGABATGGG \\
Tir270-F & TIR & TATGCTACRTCDAGNTGGTGC \\
Tir300-F & TIR & NTAGTRAAGAYATGGAATGC \\
Lrr3050-R & LRR & YGATGGTGGAACCAHCTTGGG \\
Lrr3150-R & LRR & CAGAGTAACATACARCAAATCCC \\
Nst9256-F & Start codon & ATGGCATCTTCTTCTTCTTCTTTTGCG \\
Nst3467-F & Start codon & ATGGCATCATCATCTTCTCCTTCTGAG \\
Nst381-F & Start codon & CTTCTTCTGCTAAATCGTCACAG \\
Nst516-F & Start codon & AGTAATTCACAATATTGTCCTCC \\
Nst911-F & Start codon & TGCAAGTAACTCACTCTACTGG \\
Nst307-F & Start codon & TCACAGTACTGTCCTCCATGG \\
Nst055-F & Start codon & TAGATCGTCGCAGTTGACTCC \\
\hline
\end{tabular}

Development of Co-segregating N-like Profiling Marker

The $N$ cluster contains a large number of $N$-like sequences that offer a good potential for marker development. The PCR products, obtained with the N2527 primers (which start at nucleotide 132 and end at 1495 after the start codon of the NL-25 sequence) on the DNA of parental and F1 individuals, were digested with several restriction enzymes in an attempt to obtain additional markers that mapped closer to Rpi-avl1. Unfortunately, the number of homologues amplified with this primer pair was so high that the digestion resulted only in a smear of fragments and no individual fragment could be identified and isolated, indicating that a higher resolution marker platform was necessary to resolve the different amplification/digestion products, hence the adaptation of the NBS profiling technique to the specific $N$-like gene family.

In a study by Bakker et al. 2011, RH89-039-16 (RH) BAC clones selected for the presence of $R$ genes, were mapped and sequenced. This sequence information in the vicinity of the $N$ cluster on the short arm of chromosome 11 was analyzed. N-like sequences from $\mathrm{RH}$ and avl478-2 were aligned and eight degenerate $N$-like profiling primers were designed on the conserved region of the three domains: TIR, NBS and LRR. Seven $N$-like profiling primers were also designed on specific and unique sequences of the start codon of different $N$-like sequences from RH BAC clones (Table 4). The 75 primer/enzyme combinations $(15$ primers $\times 5$ enzymes) were tested on the parents and on the bulks of resistant and susceptible individuals. This screen resulted in $11 \mathrm{~N}$-like profiling markers that were putatively linked with the $R$ gene, six of which were confirmed to be associated on the F1 individuals. Five of those markers still mapped a few recombinants away from the gene and were therefore not informative. One marker showed 100\% linkage with the resistance (Nst9256-BspL) (Fig. 3). The primer Nst9256-F is a specific primer designed on the start codon of two similar RH sequences from the BAC clones RH170N15 and RH125M10 and both were mapped in RH Bin 4. This indicates that the Rpi-avll gene indeed lies within an $N$ gene like cluster and that it is highly likely that Rpi-avll is an $N$ gene homologue.

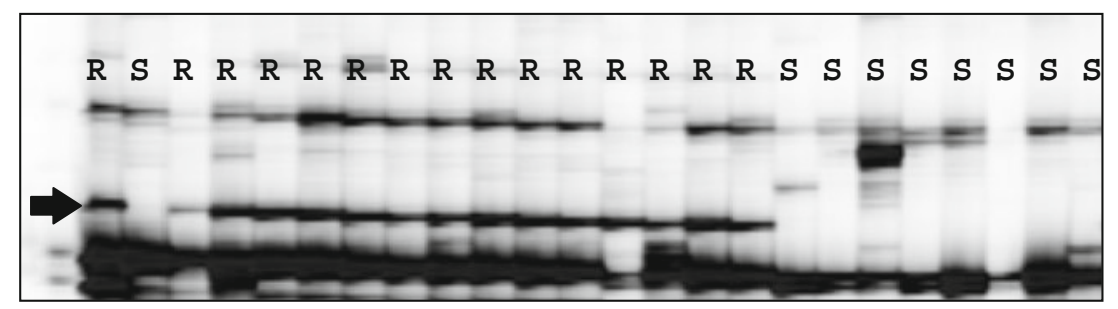

Fig. $3 \mathrm{~N}$ profiling marker in coupling phase (Nst9256-BspL, arrow) cosegregating with the resistance in 3890 individuals. The first two samples are the parents, followed by the closest F1 recombinant individuals grouped as 14 resistant and 8 susceptible genotypes, indicated by $\mathrm{R}$ and $\mathrm{S}$, respectively 


\section{Discussion}

The search for late blight resistance of South American origin led to the mapping of Rpi-avll, an $R$ gene from the Bolivian species $S$. avilesii. Rpi-avll is located on the short arm of chromosome 11 in the so-called $N$ cluster. The $N$ cluster is a hot spot for resistance (Gebhardt and Valkonen 2001) with genes conferring resistance to many pathogens including nematodes, bacteria, fungi and viruses (Brown et al. 1996; Hämäläinen et al. 1997 \& 1998; Hehl et al. 1999; Zimnoch-Guzowska et al. 2000). So far Rpi-avll is the first major $R$ gene to late blight to be mapped in this cluster, in addition to a minor QTL conferring resistance to late blight (Leonards-Schippers et al. 1994; Oberhagemann et al. 1999).

The gene family specific marker approach, which in this case was based on the knowledge that the $N$ cluster contains many $N$-like sequences, enabled the development of a marker that co-segregated with Rpi-avll. The specific primers mainly target the $N$ cluster on chromosome 11, the largest cluster containing genes from the $N$ family in potato. This approach with $N$-like specific and degenerated primers allows the development of co-segregating and flanking markers. The developed markers could be used to select for recombination events to reduce the size of the introgression, and hence minimize undesired linkage drag. It must be realized that during the process of introgression breeding with $S$. tuberosum as recurrent parent, the frequency of cross-over events in the introgressed "hybrid" region of the chromosome is often reduced, especially if the donor accession is a distant wild relative. The presence of $\mathrm{N}$-like sequences at the Rpi-avll locus and the identification of the $N$-like marker that co-segregates with the resistance against $P$. infestans, strongly suggests that Rpi-avll is an $N$ like $R$ gene.

Rpi-avl1 conferred resistance to a relatively broad spectrum of different $P$. infestans isolates. It was not effective against two isolates, and hence, may not be expected to contribute to a durable protection against late blight, unless used in combination with other $R$ genes. Additional isolates should be tested to obtain a more comprehensive impression on the resistance spectrum. The resistance reaction in the detached leaf assay was not in all cases sufficient to fully arrest lesion development, but did reduce pathogen growth, resulting in lesions that were smaller than those of fully susceptible leaves. This is different from the observation in the field where a stronger resistance reaction occurred. Rpi-avll could be an interesting gene to use in combination with other strong Rpi genes.

The $N$ gene of $N$. tabacum consists of five introns and six exons and belongs to the TIR-NBS-LRR class of $R$ genes, which allows the splicing of different variants from the same pre-mRNA (Kazan 2003). Dinesh-Kumar et al.
(2000) indeed found the presence of two splicing variants of the tobacco $N$ gene with a specific abundance ratio depending on pathogen challenge and necessity for the resistance. Other intron-containing genes are predicted to encode multiple variants (Jordan et al. 2002). In these cases, the ratio between the two splicing variants might be easily disturbed, which could affect the level of resistance. If a similar situation applies to Rpi-avll, this could explain the variation of the resistance reaction with aging of the plant. Future cloning of the gene will enable gene expression analysis and gene splicing studies, giving insight into the working mechanism of this Rpi gene. Moreover, once cloned, the $R$ gene will allow the efficient screening of $P$. infestans effector libraries for the corresponding Avr gene, as described in Oh et al. (2009). Rpi genes with different mechanisms and belonging to different clusters might be complementary in action, and their stacking might result in durably effective resistance. Such an $R$ gene combination may be achieved by introgression breeding or more easily by genetic modification of existing varieties with major Rpi genes.

The markers and materials developed in this study offer good perspectives for the cloning of Rpi-avll. The availability of the potato genome sequence and the isolation of the corresponding avirulence gene will facilitate this process (http://www.potatogenome.net). At this moment, Rpi-avll could already be introduced in a conventional potato breeding program and be selected for with the cosegregating $N$-like marker.

Acknowledgements The authors like to thank Gert van Arkel for DNA isolation and technical support and Jack Vossen for NBS profiling on $\mathrm{RH}$.

Open Access This article is distributed under the terms of the Creative Commons Attribution Noncommercial License which permits any noncommercial use, distribution, and reproduction in any medium, provided the original author(s) and source are credited.

\section{References}

Bai, Y., et al. 2004. A set of simple PCR markers converted from sequence specific RFLP markers on tomato chromosomes 9 to 12. Molecular Breeding 13: 281-287.

Bakker, E., et al. 2011. A genome-wide genetic map of NB-LRR disease resistance loci in potato. Theoretical and Applied Genetics 123: 493-508.

Barone, A. 2004. Molecular marker-assisted selection for potato breeding. American Journal of Potato Research 81: 111-117.

Borm, T.J.A. 2008. Construction and use of a physical map of potato. $\mathrm{PhD}$ thesis Wageningen University, Wageningen.

Brigneti, G., et al. 1997. Molecular mapping of the potato virus Y resistance gene $R y($ sto $)$ in potato. Theoretical and Applied Genetics 94: 198-203.

Brown, C.R., et al. 1996. RFLP analysis of resistance to Columbia root-knot nematode derived from Solanum bulbocastanum in a BC2 population. Theoretical and Applied Genetics 92: 572-576. 
Champouret, N., et al. 2009. Phytophthora infestans isolates lacking class I ipiO variants are virulent on Rpi-blb1 potato. Molecular Plant-Microbe Interactions 22: 1535-1545.

Collard, B.C.Y., et al. 2005. Development of molecular markers for crown rot resistance in wheat: mapping of QTLs for seedling resistance in a '2-49' x 'Janz' population. Plant Breeding 124: 532-537.

Collins, A., et al. 1999. QTL for field resistance to late blight in potato are strongly correlated with maturity and vigour. Molecular Breeding 5: 387-398.

Colon, L.T., and D.J. Budding. 1988. Resistance to late blight (Phytophthora-infestans) in 10 wild Solanum species. Euphytica 77-86.

Dinesh-Kumar, S.P., et al. 2000. Structure-function analysis of the tobacco mosaic virus resistance gene $N$. Proceedings of the National Academy of Sciences of the United States of America 97: 14789-14794.

Feingold, S., et al. 2005. Mapping and characterization of new ESTderived microsatellites for potato (Solanum tuberosum L.). Theoretical and Applied Genetics 111: 456-466.

Fry, W.E. 1978. Quantification of general resistance of potato cultivars and fungicide effects for integrated control of potato late blight. Phytopathology 68: 1650-1655.

Gabriel, J.L., et al. 2001. Experiencias y Logros sobre Mejoramiento Convencional y Selección Participativa de Cultivares de Papa en Bolivia. Revista Latinoamericana de la Papa 12: 169-192.

Gebhardt, C., and J.P.T. Valkonen. 2001. Organization of genes controlling disease resistance in the potato genome. Annual Review of Phytopathology 39: 79-102.

Ghislain, M., et al. 2004. Selection of highly informative and userfriendly microsatellites (SSRs) for genotyping of cultivated potato. Theoretical and Applied Genetics 108: 881-890.

Hämäläinen, J.H., et al. 1997. Mapping and marker-assisted selection for a gene for extreme resistance to potato virus Y. Theoretical and Applied Genetics 94: 192-197.

Hämäläinen, J.H., et al. 1998. Molecular examination of a chromosome region that controls resistance to potato $\mathrm{Y}$ and A potyviruses in potato. Theoretical and Applied Genetics 96: 1036-1043.

Haverkort, A.J., et al. 2008. Societal costs of late blight in potato and prospects of durable resistance through cisgenic modification. Potato Research 51: 47-57.

Hawkes, J. 1990. The potato: Evolution, biodiversity, and genetic resources. London: Belhaven.

Hehl, R., et al. 1999. TMV resistance gene $N$ homologues are linked to Synchytrium endobioticum resistance in potato. Theoretical and Applied Genetics 98: 379-386.

Huang, S. 2005. Discovery and characterization of the major late blight resistance complex in potato. $\mathrm{PhD}$ thesis Wageningen University, Wageningen.

Jacobsen, E., and H.J. Schouten. 2007. Cisgenesis strongly improves introgression breeding and induced translocation breeding of plants. Trends in Biotechnology 25: 219-223.

Jordan, T., et al. 2002. Alternative splicing of transcripts encoding toll-like plant resistance proteins - What's the functional relevance to innate immunity? Trends in Plant Science 7: 392 398.

Kazan, K. 2003. Alternative splicing and proteome diversity in plants: The tip of the iceberg has just emerged. Trends in Plant Science 8: 468-471.

Leonards-Schippers, C., et al. 1994. Quantitative resistance to Phytophthora infestans in potato: A case study for QTL mapping in an allogamous plant species. Genetics 137: 67-77.

Malcolmson, J.F., and W. Black. 1966. New $R$ genes in Solanum demissum lindl. and their complementary races of Phytophthora infestans (Mont.) de bary. Euphytica 15: 199-203.

Michelmore, R.W., et al. 1991. Identification of markers linked to disease-resistance genes by bulked segregant analysis - a rapid method to detect markers in specific genomic regions by using segregating populations. Proceedings of the National Academy of Sciences of the United States of America 88: 9828-9832.

Oberhagemann, P., et al. 1999. A genetic analysis of quantitative resistance to late blight in potato: Towards marker-assisted selection. Molecular Breeding 5: 399-415.

Oh, S.K., et al. 2009. In Planta Expression Screens of Phytophthora infestans RXLR Effectors Reveal Diverse Phenotypes, Including Activation of the Solanum bulbocastanum Disease Resistance Protein Rpi-blb2 ${ }^{[\mathrm{W}]}$. Plant Cell 21: 2928-2947.

Ruiz de Galarreta, J., et al. 1998. Wild Solanum species as resistance sources against different pathogens of potato. Potato Research 41: $57-68$.

Song, J., et al. 2003. Gene RB from Solanum bulbocastanum confers broad spectrum resistance against potato late blight pathogen Phytophthora infestans. Proceedings of the National Academy of Sciences 100: 9128-9133.

van der Linden, C.G., et al. 2004. Efficient targeting of plant disease resistance loci using NBS profiling. Theoretical and Applied Genetics 109: 384-393.

van der Vossen, E., et al. 2003. An ancient $R$ gene from the wild potato species Solanum bulbocastanum confers broad-spectrum resistance to Phytophthora infestans in cultivated potato and tomato. Plant Journal 36: 867-882.

Vidal, S., et al. 2002. Potato gene $Y-1$ is an $N$ gene homolog that confers cell death upon infection with potato virus $Y$. Molecular Plant-Microbe Interactions 15: 717-727.

Vleeshouwers, V., et al. 1999. A laboratory assay for Phytophthora infestans resistance in various Solanum species reflects the field situation. European Journal of Plant Pathology 105: 241-250.

Wang, H., et al. 1993. A simple method of preparing plant-samples for PCR. Nucleic Acids Research 21: 4153-4154.

Wastie, R.L. 1991. Resistance to powdery scab of seedling progenies of Solanum tuberosum. Potato Research 34: 249-252.

Whitham, S., et al. 1994. The product of the tobacco mosaic virus resistance gene $N$ : Similarity to toll and the interleukin-1 receptor. Cell 78: 1101-1115.

Zimnoch-Guzowska, E., et al. 2000. QTL analysis of new sources of resistance to Erwinia carotovora ssp. atroseptica in potato done by AFLP, RFLP, and resistance-gene-Like markers. Crop Science 40: $1156-1167$ 